time of the operation but also because inpatient investigations and treatment are necessary.

Revision operations take longer to perform than the equivalent primary procedure and are certainly more expensive in terms of the consumable items used. Twenty five out of 36 of the exchange arthroplasties used cement impregnated with antibiotic, and 27 required non-standard implants.

The cost of antibiotics was over 10 times that incurred with primary surgery because combined, often parenteral, treatment with expensive drugs was given for long periods.

To reduce the costs to the patient and the NHS all efforts must ensure that a primary joint replacement is as successful as possible. We caution against short term economies, which may well produce considerable clinical and financial burdens in the long term.

We thank Miss Margaret Richardson, principal pharmacist, and theatre sisters Margaret Douglas and Pat McDonald for their invaluable help, and the consultant orthopaedic surgeons of Gartnavel General Hospital for allowing their patients to be included in the study.

1 Williams A. Economics of coronary artery bypass grafting. Br Med 1985:291:326-9.

2 Dreghorn CR, Roughneen P, Graham J, Hamblen DL. The real cost of join replacement. Br.Med F 1986;292:1636-7.

Accepted 2 December 1988

\section{Retention of skills by advanced trained ambulance staff: implications for monitoring and retraining}

\section{Geraldine Walters, Edward Glucksman}

Accident and Emergency

Department, King's College Hospital, London SE5 9RS

Geraldine Walters, BSC, research associate

Edward Glucksman, FRCP, consultant

Correspondence to: $\mathrm{Ms}$ Walters.

BrMed f 1989;298:649-50
In the United Kingdom there are no formal recommendations for monitoring ambulance staff who have training in advanced cardiac life support skills. Although the NHS Training Authority's guidelines for extended training of ambulance staff describe the content of courses in detail, recommendations for monitoring standards are limited. ${ }^{1}$ To assess the need for monitoring we evaluated the performance of ambulance staff who had been trained in advanced cardiac life support skills but had not been formally monitored or retrained over two years.

\section{Subjects, methods, and results}

In 1985, 17 ambulance staff in London were trained in advanced cardiac life support skills. The table shows the training programme and protocols of treatment. After the training they submitted reports and electrocardiograms/audiocassette tapes (dual channel cassette tapes providing an electrocardiogram and audible record of the incident) on all patients requiring advanced skills. In 1987 all reports and tapes available for these patients were assessed for recognition of rhythms; correct treatment of arrhythmias according to the protocols; compliance with the sequence of treatment stated in the protocols; quality of the electrocardiogram; time to direct current shock (for patients found in ventricular fibrillation); and continuity of basic life support.

From 99 cases of cardiac arrest 57 tapes were available for assessment. In 100 out of 111 episodes the rhythm was accurately recognised. Drugs were given correctly in 49 out of 57 cases. Defibrillation was attempted on 54 occasions: 34 were appropriate and nine inappropriate, and in 11 cases assessing whether the shock was appropriate was impossible because of inadequate or missing electrocardiograms. In nine patients some of the treatment was given on the basis of inadequate electrocardiograms. On two occasions the electrocardiograph's "gain" seemed to have been turned down. On four occasions "quick look" paddles were used but the resulting trace was inadequate, and on three occasions the trace was distorted by artefact. In 17 cases the patient was intubated or moved to the ambulance before electrocardiograph leads were applied. The mean time from arrival of the ambulance crew to delivery of the first shock was $4 \cdot 3$ (SD 2.7) minutes (range 1-9 minutes; 27 cases assessed). The mean time from the first appearance of ventricular fibrillation on the oscilloscope to delivery of the first shock was 66 (46) seconds (range 22-221 seconds). Interruptions to basic life support of longer than 30 seconds occurred in 23 cases.

\section{Comment}

The ambulance staff showed a good knowledge of the protocols of treatment and the electrocardiographic more common and resulted in delays in defibrillation (often secondary to the patient being intubated or moved before electrocardiograph leads were applied), interruptions to basic life support, and the risk of inappropriate treatment as a result of an inadequate electrocardiogram. Improvement in these would have optimised the lifesaving capabilities of the staff, but as the staff did not receive any feedback they were probably unaware of how they might improve their performance.

The results suggest that the initial training programme was sufficient in theoretical content but required more emphasis on practical aspects. The protocol was not clear about what equipment and procedures should be used first when attending a possible cardiac arrest. Monitoring of staff is therefore necessary to assess the adequacy of the initial training programme, to evaluate how training translates into practice, and to identify aspects in which retraining is required.

Review of electrocardiograms/audiocassette tapes in rhythms encountered. Errors in applying skills were

Details of advanced training programme (full programme lasts six weeks) and protocols of treatment for ambulance staff

\begin{tabular}{|c|c|c|c|c|}
\hline Staff eligible for programme & Content of course & Assessment & Training given by & Practical skills acquired \\
\hline Selected staff & $\begin{array}{l}\text { Two weeks' } \\
\text { theoretical work }\end{array}$ & Written examination & $\begin{array}{l}\text { Hospital consultants and ambulance } \\
\text { instructors }\end{array}$ & Cardiac monitoring \\
\hline $\begin{array}{l}\text { Staff trained in intubation } \\
\text { and infusion }\end{array}$ & $\begin{array}{l}\text { One week's practical } \\
\text { work in classroom }\end{array}$ & Oral examination & & Use of defibrillator \\
\hline $\begin{array}{l}\text { Staff able to pass written } \\
\text { test before course }\end{array}$ & $\begin{array}{l}\text { Three weeks' practical } \\
\text { work in hospital }\end{array}$ & $\begin{array}{l}\text { Practical assessment } \\
\text { with manikin }\end{array}$ & & $\begin{array}{l}\text { Administration of selected } \\
\text { drugs by endotracheal tube } \\
\text { and intravenous routes } \\
\text { according to set protocols }\end{array}$ \\
\hline
\end{tabular}

*Ventricular fibrillation: precordial thump $\rightarrow$ shock $200 \mathrm{~J} \rightarrow$ shock $200 \mathrm{~J} \rightarrow$ shock $400 \mathrm{~J} \rightarrow$ intubation $\rightarrow$ lignocaine $200 \mathrm{mg} \rightarrow$ shock $400 \mathrm{~J} \rightarrow$ adrenaline $(20 \mathrm{ml}) 1 / 10000 \rightarrow$ shock $400 \mathrm{~J}$. Asystole: intubation $\rightarrow$ atropine $2 \mathrm{mg} \rightarrow$ adrenaline $(20 \mathrm{ml}) 1 / 10000 \rightarrow$ isoprenaline $100 \mu \mathrm{g}$ 
addition to written reports is required to gain a comprehensive view of performance. In the United States this type of monitoring by a physician is recommended for all cases of cardiac arrest treated by emergency medical technicians using advanced skills. No such recommendations exist in the United Kingdom. Monitoring of electrocardiograms and cassette tapes is time consuming and requires additional equipment. ${ }^{3}$ Lack of resources or medical support, in addition to the lack of official directives, may result in ambulance services failing to monitor standards, and the full potential of advanced trained ambulance staff will not be achieved.
We thank Marks and Spencer for funding this research, Miss S Smith for preparing the manuscript, and Dr D D'Auria, Mr K G Smith, and the staff of the London Ambulance Service for allowing access to records and equipment.

Ambulance Staff Training Committee. Extended training in ambulance aid. Bristol: NHS Training Authority, 1987

2 Cummins RO. EMT defibrillation: national guide-lines for implementation. Am 7 Emerg Med 1987:5:254-7.

3 Cummins RO, Austin D, Graves JR, et al. An innovative approach to medical control: semi-automatic defibrillators with solid-state memory modules for recording cardiac arrest events. Ann Emerg Med 1988;17:818-24.

Accepted 23 December 1988)

\section{Screening for colonic cancer in patients with Barrett's oesophagus}

\section{A F Robertson, R C S Ayres, C L Smith}

Department of Medicine II, Southampton General Hospital, Southampton SO9 4XY

D A F Robertson, MD, lecturer in medicine R C S Ayres, MRCP, medical registrar C L Smith, MD, senior lecturer in medicine

Correspondence to: $\mathrm{Dr}$ Robertson.

BrMed f 1989;298:650
In 1985 Sontag et al reported an association between Barrett's oesophagus and colonic neoplasia, but their study did not include a control population. 'In another uncontrolled series no colorectal cancers were seen in 36 patients with Barrett's oesophagus, although $33 \%$ of these patients had colorectal adenomas. ${ }^{2}$ We performed colonoscopy prospectively in our patients with Barrett's oesophagus, none of whom had symptoms of colonic neoplasia, and compared the results with those obtained in a control group of patients thought to have the irritable bowel syndrome.

\section{Subjects, methods, and results}

Barrett's oesophagus was defined as columnar epithelium occurring in a tubular oesophagus at least $3 \mathrm{~cm}$ above the manometrically defined lower oesophageal sphincter. ${ }^{+}$We studied 32 patients $(21$ men and 11 women), whose mean age was 61 (range 29-81). None had a history of colorectal neoplasia. Two control patients thought on clinical grounds to have the irritable bowel syndrome, and matched for age and sex, were chosen for each patient with Barrett's oesophagus; their mean age was 55 (range 28-81). No additional screening tests, such as testing for faecal occult blood, were done to exclude colonic neoplasia.

Eight patients with Barrett's oesophagus (25\%) had 12 colorectal tumours, three of which were malignant and nine benign (table). All were successfully treated, two by local resection, one by subtotal colectomy, and

Clinical details of patients and controls with colorectal tumours

\begin{tabular}{|c|c|c|c|c|}
\hline Case No & $\begin{array}{l}\text { Age (years) } \\
\text { and sex }\end{array}$ & Site & Histological findings & Treatment \\
\hline \multicolumn{5}{|c|}{ Patients } \\
\hline 1 & $79 \mathrm{M}$ & Sigmoid colon & Tubulovillous adenoma with severe & Endoscopic polypectomy \\
\hline 2 & & (Descending colon & dysplasia at both sites & \\
\hline 2 & $66 \mathrm{M}$ & Descending colon & $\begin{array}{l}\text { Tubulovillous adenoma with severe } \\
\text { dysplasia }\end{array}$ & Endoscopic polypectomy \\
\hline 3 & $53 \mathrm{M}$ & Sigmoid colon & $\begin{array}{l}\text { Tubular adenoma and mild } \\
\text { dysplasia at two sites }\end{array}$ & Endoscopic polypectomy \\
\hline 4 & $72 \mathrm{~F}$ & Hepatic flexure & Adenomatous polyp & Endoscopic polypectomy \\
\hline 5 & $74 M$ & Sigmoid colon & Adenomatous polyp & Endoscopic polypectomy \\
\hline \multirow{3}{*}{6} & \multirow{3}{*}{$52 M$} & Transverse colon & Tubular adenoma with mild & Right hemicolectomy \\
\hline & & & dysplasia & \\
\hline & & Hepatic flexure & Dukes's A carcinoma & \\
\hline 7 & $44 M$ & $\left\{\begin{array}{l}\text { Splenic flexure } \\
\text { Sigmoid }\end{array}\right.$ & Dukes's B carcinoma & Subtotal colectomy \\
\hline \multirow[t]{2}{*}{8} & $71 M$ & Sigmoid colon & Dukes's A carcinoma & Sigmoid colectomy \\
\hline & & & Controls & \\
\hline 9 & $52 M$ & Sigmoid colon & Adenomatous polyp & Endoscopic polypectomy \\
\hline 10 & $64 \mathrm{~F}$ & Descending colon & Adenomatous polyp & Endoscopic polypectomy \\
\hline 11 & $66 \mathrm{M}$ & Rectum & Adenomatous polyp & Endoscopic polypectomy \\
\hline
\end{tabular}

five by endoscopic polypectomy. Three of the 64 controls $(5 \%)$ had single adenomatous polyps, which were removed endoscopically. The relative risk of colonic tumour was 5.3 in the patients with Barrett's oesophagus ( $95 \%$ confidence interval 1.94 to $8 \cdot 69$ ).

\section{Comment}

We found a high prevalence of colorectal tumours in our patients with Barrett's oesophagus, in keeping with the findings of Sontag et al. ${ }^{1}$ Our study was entirely prospective, and the association between colonic neoplasia and Barrett's oesophagus seemed to be genuine and not due to some hidden bias; this may not have been the case in the uncontrolled study by Sontag et $a l$, in which seven of 10 carcinomas were identified retrospectively.

Selecting an appropriate control group was difficult, and we considered that colonoscopic examination of asymptomatic people was unjustified because of the risks and discomfort entailed. We thus selected patients who had been referred for investigation and in whom the irritable bowel syndrome had been diagnosed on clinical grounds. The controls were on average six years younger than the study group, and this could have affected the prevalence of colonic tumours: the prevalence of colonic neoplasia related to age in asymptomatic subjects is unknown. The difference in age between the two groups, however, is unlikely to have accounted for all of the observed differences in prevalence.

The aetiology of both Barrett's oesophagus and carcinoma of the colon remains unknown. The symptoms of dyspepsia or chest pain are unlikely to have been caused by the colonic carcinoma or adenoma, and in each case the finding of a colonic lesion was incidental. An inherited or acquired common aetiological agent, such as a dietary factor or a tendency to neoplastic or metaplastic change throughout the gastrointestinal tract, may have been the cause. There was no evidence of dysplasia in biopsy specimens or resected colonic epithelium not affected by adenomatous or carcinomatous change.

It has been recommended that frequent oesophagoscopy should be undertaken in patients with Barrett's oesophagus to detect early oesophageal carcinoma or dysplasia. None of our patients had high grade dysplasia or oesophageal carcinoma but eight had colonic neoplasia. Colonoscopy may therefore be a more worthwhile screening procedure for cancer than oesophagoscopy in Barrett's oesophagus.

1 Sontag SJ, Schnell TG, Chesec G, et al. Barrett's (esophagus and colonic tumours. Lancet 1985; ; $946-9$.

2 Tripp MR, Sampliner RE, Kogan FJ, Morgan TR. Colorectal neoplasia and Barreti's Ses

Barrett's oesophagus. Am f Gastroenterol 1986;81:1063-4. Towards positive
. Manning AP, Thompson WG, Heaton KW, Morris AF.

diagnosis of the irritable bowel. Br.Med f 1978;ii:653-4.
Spechler SJ, Goval RK. Barrett's oesophagus. N Engl J Med 1986;315:362-71

Accepted 23 December 1988 